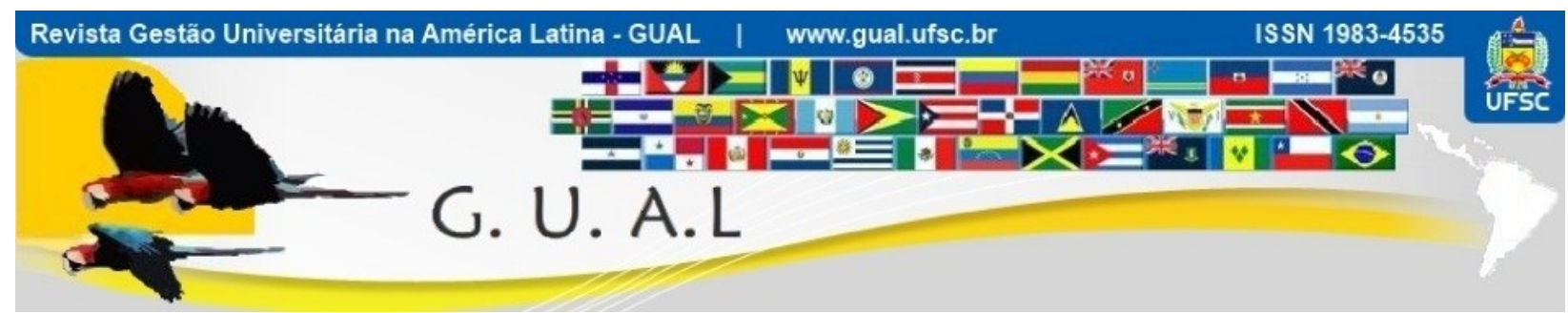

DOI: http://dx.doi.org/10.5007/1983-4535.2012v5n4p1

\title{
DESAFIOS DO FINANCIAMENTO DAS UNIVERSIDADES ESTADUAIS PAULISTAS
}

THE FINANCING OF STATE UNIVERSITIES OF SÃO PAULO

\begin{abstract}
Alberto Teixeira Protti, Mestre Universidade de São Paulo - USP abprotti@usp.br

Carlos Antonio Luque, Doutor Universidade de São Paulo - USP cluque@usp.br

Hélio Nogueira da Cruz, Doutor Universidade de São Paulo - USP hncruz@usp.br
\end{abstract}

Recebido em 16/novembro/2012

Aprovado em 07/dezembro/2012

Sistema de Avaliação: Double Blind Review

Esta obra está sob uma Licença Creative Commons Atribuição-Uso. 


\title{
RESUMO
}

O presente artigo trata dos desafios do financiamento das Universidades Estaduais Paulistas frente ao aumento da demanda por vagas nos seus cursos de graduação e ao crescimento das pressões sobre o orçamento do setor educacional do Estado, em decorrência da recente eleveção do percentual mínimo de aplicação de recursos na educação básica definido pelo FUNDEB. Desde o final dos anos 80, as Universidades Estaduais Paulistas possuem suas receitas vinculadas à arrecadação do ICMS. Entretanto, ao contrário da educação básica, cuja vinculação decorre de dispositivo constitucional, a vinculação das universidades apresenta uma maior fragilidade, uma vez que é definida a cada ano por meio da Lei de Diretrizes Orçamentárias do Estado. Possíveis pressões por aumento de recursos poderão ser mais facilmente acomodadas diante de um cenário de crescimento econômico mais robusto. Caso contrário, as Universidades Estaduais precisarão encontrar alternativas para o financiamento de sua expansão.

Palavras-chave: Financiamento do ensino superior. Universidades Estaduais Paulistas. Expansão de vagas na graduação. Ensino público superior.

\begin{abstract}
This paper discusses the financing of State Universities of São Paulo in front of the increase of yearly enrollment in undergraduate courses and the growth of pressure on the Education System's budget after the rise in the minimum percentage of investment in basic education approved by the Brazilian Congress. Since 1989 the State Universities of São Paulo have been treated as autonomous institutions and their budgets linked to ICMS, one of the most important taxes of state of São Paulo. However, this pattern of financing is fragile because it depends on the approval of state assembly, while the investment in basic education is defined by the Constitution. In the case of shortage of financial resources this fragility may become relevant and the Universities may have to deal with a budget reduction or find alternatives to their funding.
\end{abstract}

Keywords: Financing of Higher Education. State Universities of São Paulo. Higher Education Expansion. Public Higher Education. 


\section{INTRODUÇÃO}

O financiamento do setor público nos países da América Latina tem recebido atenção durante as últimas décadas fruto das tradicionais dificuldades que esses países revelam para equilibrar seus orçamentos. Ainda que após o Plano Real o Brasil tenha conseguido estabilizar suas taxas de inflação em patamares reduzidos, a questão do financiamento público representa um dos principais temas discutidos em nossa sociedade.

Essa discussão acabou se traduzindo num debate intenso sobre os custos dos serviços públicos argumentando-se que a sociedade brasileira arca com uma das maiores cargas tributárias a nível mundial e recebe serviços públicos de péssima qualidade. As próprias instituições públicas passaram a buscar desenvolver mecanismos de avaliação de sua atuação bem como a aferição dos custos de seus serviços com o objetivo de desenvolver mecanismos de gestão mais adequados.

Esse intenso debate refletiu-se também para o setor da Educação e particularmente do Ensino superior. O financiamento da educação superior tem alcançado muito destaque na maioria dos países fruto da crescente demanda pelo ensino superior e da pressão crescente sobre os orçamentos públicos. Desta maneira, existe um movimento muito claro de alteração dos padrões de financiamento, buscando-se alternativas para a tradicional forma representada pelos recursos públicos provenientes do sistema orçamentário. Atualmente, as fontes de financiamento representadas pelo pagamento de mensalidades e a venda de serviços $\mathrm{O}$ estágio atual é marcado pelo crescimento das fontes representadas pelo pagamento de mensalidades ou através de projetos de pesquisa junto ao setor privado. (Johnstone, 2006 ; Jongbloed, 2008, entre outros).

No caso do Brasil o financiamento da educação superior pública adquire adicionalmente outras dimensões em função de algumas características especificas da economia brasileira. Em particular destaca-se a própria distribuição de renda, pois se argumenta que a distribuição da produção gerada em nossa economia, ao concentrar-se na mão de pequena parcela da população, reduz a oportunidade para a maioria dos jovens provenientes das famílias mais pobres. Dessa forma, a parcela de jovens inseridos nas instituições de ensino superior é muito reduzida especialmente nas instituições públicas que de acordo com o artigo 206 da Constituição Federal será gratuito nos estabelecimentos oficiais. É alegado que os jovens que ingressam nas instituições de ensino superior são em sua maioria provenientes de famílias com maior poder aquisitivo. 
Por outro lado, assim como em todos os outros segmentos de atuação do setor público, argumenta-se que o financiamento do ensino superior é efetuado sem a contrapartida de uma apresentação mais clara dos serviços produzidos para a sociedade. Dessa maneira, a sociedade como um todo estaria transferindo elevado volume de recursos para as universidades públicas, que atendem majoritariamente camadas mais ricas da população.

Em suma, o financiamento das instituições públicas de ensino superior tem sido questionado na maioria dos países em particular no Brasil, fruto de todas as criticas tradicionalmente efetuadas sobre a atuação do setor público em nosso país.

O objetivo deste artigo reside justamente em analisar os desafios de financiamento das instituições públicas de ensino superior, em particular, das Universidades Estaduais Paulistas (USP, UNICAMP e UNESP), que possuem um mecanismo de financiamento peculiar, caracterizado pela vinculação de parcela da receita proveniente do Imposto sobre Circulação de Mercadorias e Serviços (ICMS).

Com tal objetivo o artigo se estrutura em três seções, além desta introdução e das conclusões. Na primeira seção apresentamos as questões mais amplas que caracterizam a discussão sobre o financiamento das instituições de ensino superior. $\mathrm{Na}$ segunda apresentamos algumas características do financiamento do ensino superior no Brasil e Estado de São Paulo. Segue-se uma seção que apresenta as características principais do financiamento das Universidades Estaduais e aponta-se alguns dos principais desafios que essas instituições devem enfrentar. Segue-se um breve sumário e conclusões do trabalho.

\section{MECANISMOS DE FINANCIAMENTO DO ENSINO SUPERIOR}

O Ensino superior tem sido apontado na maioria dos estudos sobre desenvolvimento econômico de fundamental importância para permitir o crescimento econômico dos países de uma maneira elevada e sustentável ao longo do tempo. Isto porque, a principal característica do processo de desenvolvimento centra-se na ideia de produzir cada vez mais bens com menores recursos produtivos e para tal é necessário contar com o progresso tecnológico e consequentemente com um sistema educacional apropriado.

Essa característica essencial do desenvolvimento, isto é, a economia de recursos produtivos por unidade de produto, vincula-se com dois fatores essenciais: a qualificação da mão de obra e o progresso tecnológico, que por sua vez, atrelam-se basicamente com o sistema educacional em especial com o ensino superior. 
Por outro lado, argumenta-se que além deste aspecto a educação de modo geral e especificamente o ensino superior promovem processos de inclusão social mais rápidos , transformando a sociedade não apenas do ponto de vista econômico, como também promovendo melhorias sociais .

Desta maneira, os serviços educacionais adquirem as características de um bem público, pois os seus benefícios alcançam toda a sociedade superando os benefícios que podem ser internalizados a nível individual.A produção de bens ou serviços que apresentam benefícios que são apropriados por outros membros da sociedade e não apenas pelos indivíduos que diretamente os adquirem geram as chamadas externalidades. Neste caso, justifica-se a participação governamental na sua produção ou financiamento.

Embora todas essas características sejam conhecidas e aceitas, o financiamento das instituições de ensino superior com base quase que exclusivamente nos recursos públicos foi sendo questionado ao longo das últimas décadas.

Inicialmente, quando o ensino superior era restrito a uma pequena parcela da população seu financiamento podia ser suportado integralmente pelos orçamentos públicos sem maiores pressões pois representava uma pequena parcela no conjuntos dos gastos públicos. A partir do momento que a demanda por ensino superior vai crescendo e o setor público vai elevando a oferta, ocorrendo o processo de massificação do ensino superior, a parcela de recursos necessária para o financiamento se eleva e as dificuldades começam a surgir.

A partir deste momento buscam-se argumentos para identificar outras fontes possíveis de financiamento. Alega-se que os beneficiários diretos desse sistema, ou seja os próprios alunos, deveriam participar do financiamento. Isto porque, eles se apropriam, pelo menos em parte, dos benefícios gerados pela educação através do aumento de suas remunerações que receberão a partir do momento que se engajam na atividade produtiva. No caso brasileiro, como argumentado inicialmente, adiciona-se outro motivo, representado pela noção de que, parcela significativa dos alunos nas instituições de ensino superior provem de famílias que possuem condições de efetuar o pagamento de ensino.

Todos esses argumentos acabam sugerindo, que pelo menos uma parcela do financiamento das instituições públicas deve ser obtido com recursos provenientes dos próprios alunos. Mecanismos de pagamento de mensalidades ou a concessão de empréstimos que serão pagos após o engajamento desses alunos nas atividades produtivas são sugeridos. 
Adicionalmente argumenta-se que as instituições do setor produtivo privado ou publico, beneficiados pelos conhecimentos gerados nas instituições de ensino superior também deveriam participar do financiamento através do financiamento de determinados projetos ou mesmo a compra de alguns serviços.

Seguindo Jongbloed (2008) a discussão dos mecanismos de financiamento envolvem duas questões. A primeira relaciona-se a como o setor público estrutura o financiamento das instituições de ensino superior. A segunda relaciona-se aos mecanismos que direcionam as instituições na busca de fundos de financiamento.

A primeira questão analisa se o financiamento governamental é direcionado basicamente para a cobertura dos custos envolvidos nas atividades das instituições ou se ele é orientado por indicadores ou metas de produção. A segunda questão relaciona-se com a orientação de mercado presente nos mecanismos de financiamento. São as decisões de financiamento centralizadas sob a orientação governamental ou as decisões apoiam-se em mecanismos de mercados cristalizados pelas decisões de consumidores e produtores. A partir dessas características Jongbloed (2008) sugere o esquema abaixo para a discussão das alternativas possíveis de financiamento.

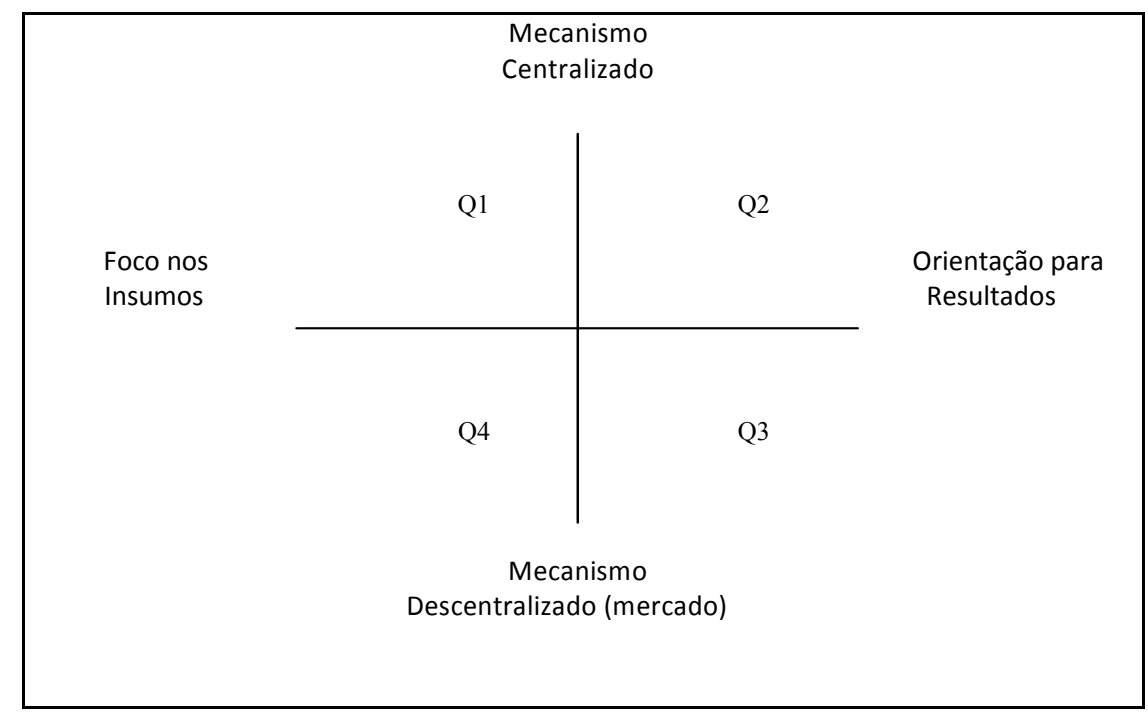

Figura 1 Sistemas de financiamento da educação superior

No eixo horizontal, os dois extremos representariam o financiamento baseado na formula tradicional de financiamento dos insumos e no outro a orientação baseada nos resultados. O eixo vertical mediria de um lado o mecanismo de financiamento centralizado no qual a estrutura de cursos seria definida de maneira mais centralizada e no outro o mecanismo dominado pelas influências dos mercados. 
A conclusão obtida por Jongbloed (2008) , Jonbloed (2004); Barr (2004) ; Lepori, Benninghoff, Jongbloed, Salerno e Slipersaeter (2005) com base na experiência dos vários países revela que o modelo de financiamento do ensino superior baseado originariamente num sistema apoiado no custeio dos insumos e centralizado do ponto de vista de decisões tem caminhado para um modelo descentralizado e orientado de maneira crescente para os resultados do setor, ou seja estaríamos passando do quadrante Q1 para o Q3.

É interessante notarmos que a importância do setor da educação superior no processo de desenvolvimento econômico aliado a suas características de bem público implicam que apesar dessas mudanças nos padrões de financiamento exige uma forte presença do setor público. Como se verifica naTabela 1, que mostra os gastos totais com a Educação Terciária, como percentual do PIB e a parcela dos gastos financiados com recursos privados e a parcela dos gastos financiados com recursos públicos. Como apontado por Jongbloed (2008) os países que destinam mais do que $2 \%$ do PIN para o ensino superior contam com recursos significativos oriundos do setor privado.

Tabela 1 Distribuição \% das fontes de financiamento das Universidades Européias - Países Selecionados (2006)

\begin{tabular}{|l|c|c|c|c|c|c|c|c|c|c|}
\hline \multicolumn{1}{|c|}{ Tipo } & UK & ES & DE & IT & NL & SE & DK & BE & IE & SWI \\
\hline $\begin{array}{l}\text { Mensalidades e Taxas } \\
\text { Acadêmicas }\end{array}$ & 23 & 16 & 1 & 12 & 7 & 0 & 0 & 5 & 32 & 3 \\
\hline Financiamento Público & 35 & 62 & 73 & 63 & 68 & 60 & 70 & 65 & 38 & 72 \\
\hline Verbas de Pesquisa & 21 & 10 & 22 & 12 & 15 & 34 & 19 & 21 & 18 & 18 \\
\hline Outras Fontes & 20 & 13 & 4 & 9 & 10 & 6 & 2 & 9 & 12 & 7 \\
\hline Total & 100 & 100 & 100 & 100 & 100 & 100 & 100 & 100 & 100 & 100 \\
\hline
\end{tabular}

Fonte: Agion et al. (2008)

A mudança apontada na forma de financiamento, orientada mais em decisões de mercado e orientada por resultados de produção explicitamente melhor definidos origina-se de um lado, pela busca das instituições de ensino superior em financiamento junto ao setor privado para a elaboração de projetos específicos e cobrança de mensalidades. Esse resultado é consequência natural das próprias pressões existentes por recursos adicionais por parte das instituições de ensino superior e das dificuldades de financiamento contando apenas com recursos orçamentários. A medida que se buscam alternativas junto aos próprios estudantes ou empresas para o financiamento de projetos de pesquisa necessariamente a observação sobre a produção efetivamente observada e uma maior sensibilidade das instituições as mudanças de mercado surgem como consequências naturais. Tanto o interesse das empresas privadas como 
dos estudantes, que devem arcar com o pagamento de mensalidades, implica numa aproximação ao mercado na qual a ênfase sobre o produto se acentua assim como a descentralização das decisões.

É interessante notar também, que embora a figura 2 permita ilustrar os mecanismos de financiamento e a sensibilidade das instituições as dinâmicas de mercado, sua interpretação deve ser efetuada com extrema cautela.Ainda que se perceba nitidamente essa tendência, fruto basicamente do próprio crescimento do setor pressionando os orçamentos públicos, é importante ressaltar que o financiamento tradicional do setor da educação superior através dos orçamentos públicos, não pode ser interpretado como se os organismos de financiamento não observassem os níveis de produção e estivessem completamente alheios às dinâmicas dos mercados. Em outras palavras, ainda que o Quadrante Q1 possa ser ilustrativo do ponto de vista analítico isto não pode ser interpretado como se os níveis de produção ou influências de mercado não exercessem nenhuma pressão sobre a dinâmica das instituições de ensino superior.

A elaboração tradicional dos orçamentos públicos baseia-se fortemente em informações sobre os custos de produção dos serviços envolvendo as despesas correntes e de capital, e não em indicadores de produção de uma maneira mais explicita. Desta maneira, alocam-se recursos para o pagamento das despesas diversas de custeio, como as despesas de pessoal, itens de custeio diversos, despesas de manutenção bem como as despesas de investimento para a ampliação das instalações, etc.

Essa forma de elaboração dos orçamentos baseia-se nas próprias características de funcionamento das instituições públicas bem como do próprio significado da contabilidade pública. Assim, como no caso de uma empresa privada ao publicar seus balanços a ênfase que se dá é sobre os diferentes tipos de despesas e não sobre os indicadores de produção. Naturalmente isto não pode ser interpretado como se os indicadores de produção estivessem completamente abandonados.

Sempre é importante lembrarmos que uma das principais características dos serviços públicos e que não são vendidos diretamente ao publico como no caso como no caso dos bens e serviços produzidos por empresas privadas. Nesse sentido a ênfase passa a ser dada para as despesas necessárias para a elaboração desses bens. Por outro lado, devemos também lembrar que embora em alguns serviços públicos a medição da produção possa ser efetuada com critérios adequados, como é o caso do setor educacional, em outras atividades a medição é muito mais complexa como é o caso dos serviços de segurança, justiça, saúde, etc. 
A elaboração dos orçamentos públicos é criticada pelo seu elevado grau de inércia, ou seja o orçamento de uma ano é carregado para o ano seguinte. É conveniente destacarmos que essa inércia na elaboração dos orçamentos reflete a própria manutenção da máquina pública que não se altera de maneira muito significativa de um ano a outro. Por outro lado, deve-se enfatizar que nos processos de elaboração orçamentária, quando se discute a expansão de recursos a serem alocados para as instituições consideram-se os níveis de produção que se buscam alcançar. Por outro lado, admitindo a existência de uma função de produção relacionando insumos com produção, desenvolver os orçamentos com base nos custos de produção equivaleria a basear o orçamento de acordo com os níveis de produção.

A outra questão apontada relaciona-se com as decisões centralizadas em contrapartida das decisões baseadas mais no sistema de mercado. É importante lembrarmos que decisões centralizadas envolvem questões administrativas, típicas do setor publico.Muitas vezes, ainda que a decisão esteja institucionalmente mais centralizada, a pressão de mercado pode estar sendo canalizada sobre os gestores públicos e consequentemente as decisões acabam refletindo informações provenientes do mercado. Não é pelo fato de que as decisões possam ser tomadas de maneira centralizada que isto significa um deslocamento total da realidade de mercado. O surgimento de novas instituições, oferecendo novos cursos, refletem a dinâmica da evolução do conhecimento e da evolução da realidade econômica e social.

\section{FINANCIAMENTO DA EDUCAÇÃO PÚBLICA SUPERIOR NO BRASIL}

Durante o processo inflacionário sofrido pela nossa economia, especialmente, a partir de meados da década de 70, alguns setores passaram a defender as chamadas vinculações orçamentárias por acreditarem que esta estratégia representaria um mecanismo adequado para a proteção de seus recursos. O conceito de vinculação orçamentária representa a orientação legal de definir o orçamento de um determinado setor com base numa outra variável nominal, usualmente, o valor dos impostos de modo geral ou algum imposto específico.

Esta estratégia é correta quando consideramos um país marcado por graves problemas econômicos e sociais que se transformam em pressões sobre os gastos públicos e consequentemente numa disputa acirrada por recursos quando da elaboração das peças orçamentárias. Ela é ainda mais importante para os setores da atividade econômica e social, que embora fundamentais para a promoção do desenvolvimento econômico não apresentem problemas que tenham uma conotação emergencial. De modo geral, as pressões por recursos acabam sendo mais bem acolhidas nos orçamentos quando o caráter emergencial é mais forte 
em detrimento dos setores, que embora essenciais para o desenvolvimento, não apresentem essa característica ou seja, são gastos fundamentais mas não apresentam a característica de serem emergenciais como é o caso dos gastos em segurança pública, saúde, etc. Este é o caso do setor educacional, que embora fundamental para o desenvolvimento econômico não revela aspectos emergenciais mais significativos.

Durante a década de 80 foi se cristalizando a ideia de que o setor educacional merecia uma proteção especial quando da elaboração dos orçamentos. O crescimento da oferta dos serviços educacionais para a promoção da universalização associava-se com a deterioração da qualidade do ensino público. Assim, argumentava-se que era necessário proteger o setor educacional nas elaborações orçamentárias e a forma mais adequada seria a vinculação orçamentária.

Desta maneira, os legisladores aprovaram na Constituição Federal de 1988 , através do artigo 212, a vinculação constitucional para a área da educação. Esse artigo estabelece que a União deverá aplicar, no mínimo , 18\% da receita de impostos incluindo às provenientes de transferências na manutenção e desenvolvimento do ensino. No caso dos Estados, Distrito Federal e Municípios, esse percentual é de 25\%.

Essa estratégia de proteção dos recursos através das vinculações orçamentárias vai ganhando adeptos e pressionando os legisladores a introduzir a outras vinculações. Desta forma, através da Emenda Constitucional n. 29, de 13 de setembro de 2000 introduziu-se a vinculação para a área da saúde.

A vinculação como mecanismo de proteção ampliou-se dentro do próprio setor educacional quando se procurou proteger os ciclos básicos da educação. Desta maneira, em setembro de 1996, através Emenda Constitucional 14, foi criado o Fundo de Manutenção e Desenvolvimento do Ensino Fundamental e de valorização do Magistério (FUNDEF), regulamentado pela Lei n. 9424 de 24 de dezembro de 1996.

A preocupação básica do FUNDEF era o desenvolvimento do ensino fundamental e para tal vinculava 15\% da receita de impostos de ICMS, Fundo de Participação dos Estados e do Distrito Federal - FPE, parcela do Imposto de Produtos Industrializados - IPI devidas aos Estados, além dos recursos transferidos aos Estados fruto a compensação financeira derivada da desoneração das exportações. (Lei Kandir)

A duração prevista do Fundef era de dez anos e assim, através da Emenda Constitucional 53/2006 foi criado o Fundo de Manutenção e Desenvolvimento da Educação Básica e de Valorização dos Profissionais da Educação Básica (FUNDEB). O FUNDEB 
ampliava os seus objetivos introduzindo os alunos do Ensino Médio e as crianças matriculadas nas creches.

O FUNDEB terá a duração de 20 anos e os percentuais de contribuição dos Estados, do Distrito Federal e Municípios foi ampliado para 20\%, em função da ampliação de seus objetivos.

Esses fatos principais da legislação revelama utilização das vinculações orçamentárias como estratégias básicas para assegurar determinados volumes de recursos para os setores considerados mais estratégicos como é o caso do setor educacional e de saúde.

\section{O DESAFIO DO FINANCIAMENTO DAS UNIVERSIDADES ESTADUAIS PAULISTAS}

Apesar do crescimento da população de 18 a 24 anos inserida em cursos de educação superior durante toda a década inicial deste século, os resultados são insatisfatórios quando comparados com outros países. Entre 2001 e 2009, a taxa de escolarização líquida cresceu de 8,9 \% para 14,4\%. No Estado de São Paulo entre 2002 e 2006 essa taxa cresceu de 9,7\% para 16,4\%. A reduzida inserção dos jovens de 18 a 24 anos dita uma pressão para que ocorra uma expansão acentuada do número de vagas nas instituições de ensino superior especialmente nas instituições públicas a partir da caracterização que parcela substancial do crescimento do número de vagas deveu-se ao crescimento das instituições privadas de ensino.

Como vimos acima alguns artigos da legislação ressaltam a importância do ensino básico no processo de desenvolvimento e a busca de preservação de recursos através das vinculações orçamentárias. Observando um pouco mais de perto a legislação atinente podemos destacar a visão governamental acerca do ensino superior.

A Constituição Federal através do seu artigo 207 afirma que “ As universidades gozam de autonomia didático-científica, administrativa e de gestão financeira e patrimonial. A Constituição do Estado de São Paulo estabelece no artigo 253 que " a organização do sistema de ensino superior será organizada para a ampliação do número de vagas oferecidas no ensino público diurno e noturno “. No seu artigo 254 estabelece que " A autonomia da universidade será exercida, respeitando nos termos de seu estatuto, a necessária democratização do ensino e a responsabilidade pública da instituição. Por outro lado, no seu artigo 255 estabelece que "O Estado aplicará, anualmente, na manutenção e no desenvolvimento do ensino público, no mínimo, trinta por cento da receita resultante de impostos, incluindo recursos provenientes de transferências". 
Seguindo a linha da autonomia universitária o Poder Executivo do Estado de São Paulo decidiu alterar profundamente o mecanismo de elaboração dos orçamentos das Universidades Estaduais Paulistas, estabelecendo, através da Lei de Diretrizes Orçamentárias uma vinculação de recursos com a arrecadação de ICMS. Desde meados da década de 90, esse repasse representa $9,57 \%$ da arrecadação de $\mathrm{ICMS}^{\mathrm{i}}$.

Desta forma, o setor educacional no Estado de São Paulo apresenta três vinculações orçamentárias. A mais ampladitada pela Constituição destinando $30 \%$ da receita liquida de impostos para o financiamento das ações de manutenção e desenvolvimento educacionais. Adicionalmente temos a vinculação do FUNDEB destinando $20 \%$ da receita de impostos e a das Universidades vinculando $9,57 \%$ da receita do ICMS.É conveniente enfatizarmos que a vinculação da Educação Básica através do FUNDEB possui base constitucional enquanto que a das universidades baseia-se numa lei anual através da Lei de Diretrizes Orçamentárias.

Durante os últimos anos, fruto do crescimento das vinculações orçamentárias, os organismos governamentais responsáveis pela elaboração dos orçamentos públicos, tem reagido a tais vinculações. Argumenta-se que a vinculação cristaliza prioridades ao longo do tempo, destinando recursos automaticamente para determinadas áreas, mesmo que inexistam projetos estruturados. Dessa maneira, as vinculações orçamentárias reduziriam a qualidade dos gastos públicos. Argumenta-se que o excesso de vinculações transforma a elaboração dos orçamentos num mero exercício de destinação de recursos previamente definidos sem os critérios tradicionais de alocação de recursos para projetos prioritários.

$\mathrm{Na}$ verdade, toda a discussão reflete basicamente a realidade econômica e social do Brasil, marcada por uma distribuição de renda altamente concentrada, traduzindo-seem elevada demanda por serviços públicos e consequentemente numa realidade orçamentária e financeira do setor público de difícil equacionamento. A disputa por recursos públicos dos vários segmentos sociais internalizam-se nos orçamentos públicos tanto a nível setorial, como educação, saúde, segurança,entre outros, com também em nível regional.

Aqueles que defendem as vinculações orçamentárias partem do principio apontado acima de que na sua ausência setores estratégicos para o desenvolvimento do país são prejudicados pois a elaboração dos orçamentos é muito mais sensível as pressões de curto prazo, oriunda de setores que eventualmente não seriam aqueles mais importantes dentro de uma visão de longo prazo.

O resultado dessas distintasvisões gera uma situação peculiar na qual ao se estabelecer um limite mínimo de recursos a serem aplicados, este limite acaba se transformando num 
limite máximo. Alcançar percentuais acima dos limites mínimos estabelecidos não é tarefa fácil dentro dos mecanismos tradicionais de elaboração das peças orçamentárias, pois, cada ponto percentual adicional passa a exigir detalhamento muito preciso dos projetos que seriam contemplados, metas a serem alcançadas pois essa elevação implica em reduções percentuais dos setores que não contam com as vinculações orçamentárias.

De qualquer maneira, no caso do Estado de São Paulo, a autonomia administrativa e financeira das Universidades adquiriu uma característica adicional representada pela vinculação dos orçamentos com base num percentual do Imposto sobre Circulação de Mercadoria e Serviços (ICMS).

Ao se estabelecer o orçamento das Universidades Estaduais a partir de um percentual da receita do ICMS assegura-se um aumento das receitas atrelado ao próprio crescimento das atividades econômicas do Estado de São Paulo. (Tabela 2). A partir do momento que se estabelece um processo orçamentário que garanta esse crescimento estabelecem-se pressões para a expansão dos serviços prestados por essas universidades especialmente a criação de vagas de graduação.

A necessidade de expansão de vagas no âmbito do ensino superior apresenta o primeiro e talvez o maior desafio a ser enfrentado pelas Universidades Estaduais. Tradicionalmente, no âmbito do setor público, os processos de expansão de serviços a fim de atender aos excessos de demanda acabam gerar por um processo gradativo e continuo de redução da qualidade. Isto porque, considerando a fragilidade financeira das contas públicas, normalmente as expansões dos serviços não são acompanhadas pelo crescimento proporcional dos recursos. A experiência da universalização do ensino fundamental e o consequente declínio da qualidade das escolas públicas é um exemplo muito marcante desse processo.

É importante salientar, que a ênfase sobre o ensino de graduação em nenhum momento significa diminuir a importância da pesquisa dentro das Universidades Paulistas. A noção de que a qualidade do ensino depende basicamente da qualidade das pesquisas realizadas deve estar sempre presente. O que se pretende enfatizar é que não se pode deixar de apontar que o ensino de graduação representa um dos principais desafios para a sociedade brasileira e paulista e consequentemente a pressão é internalizada dentro dos organismos centrais de planejamento da ação do governo.

Por outro lado, as vinculações acima demonstram que simplesmente somando-se o percentual que deve ser aplicado no FUNDEB e nas Universidades Estaduais, chega-se ao valor de $29,57 \%$ da receita, ou seja , praticamente o limite constitucional. Admitindo-se que 
inexistissem outras pressões, o limite constitucional estaria sendo atendido e tanto os recursos destinados ao ensino básico como ao ensino superior tenderiam a crescer no montante de crescimento do ICMS que estaria condicionado ao crescimento das atividades econômicas no Estado de São Paulo, representadas pelo crescimento do PIB.

Entretanto, com a universalização do ensino fundamental no Estado de São Paulo e a crescente cobertura para o Ensino Médio existirão pressões adicionais para a expansão do Ensino Superior que se somarão ao fato de que o grau de inserção dos jovens entre 18 e 24 anos é significativamente menor no caso do Brasil do que em outros países.

$\mathrm{Na}$ realidade este processo de expansão já esta em curso e deverá manter-se nos próximos anos enquanto não atingirmos os níveis de cobertura semelhantes aos de países semelhantes do ponto de vista econômico. Como se observa na Tabela 2, a arrecadação do ICMS , com exceção do ano de 2009, teve um crescimento bastante significativo. Em 2007 cresceu 10,5\%; 20,7\% em 2008, 3,0\% em 2009, 17\% em 2010 e 10\% em 2011. Portanto este é um período cuja fonte de financiamento das Universidades elevou-se de maneira significativa.

Tabela 2 Demonstrativo da Aplicação dos Recursos de Impostos em Educação no Estado de São Paulo - 2007 a 2012 (R\$ bilhões)

\begin{tabular}{lcccccc}
\hline \multicolumn{1}{c}{ Item } & $\mathbf{2 0 0 7}$ & $\mathbf{2 0 0 8}$ & $\mathbf{2 0 0 9}$ & $\mathbf{2 0 1 0}$ & $\mathbf{2 0 1 1}$ & $\mathbf{2 0 1 2}^{(*)}$ \\
\hline Receita Líquida de Impostos & 55,2 & 66,3 & 67,7 & 79,4 & 87,6 & 93,8 \\
Secretaria Educação & 11,9 & 14,2 & 14,5 & 16,9 & 18,6 & 20,2 \\
CEET Paula Souza & 0,4 & 0,7 & 1,0 & 1,2 & 1,3 & 1,3 \\
Universidades & 4,2 & 4,9 & 4,9 & 5,9 & 6,4 & 6,7 \\
Outras & 0,0 & 0,2 & 0,2 & 0,2 & 0,4 & 0,2 \\
\hline Total Educação & 16,6 & 20,0 & 20,6 & 24,2 & 26,7 & 28,4 \\
\hline
\end{tabular}

Fonte: Secretaria de Desenvolvimento e Planejamento Regional do Estado de São Paulo. *Previsão Inicial

A tabela 2 apresenta também a aplicação de recursos para a área educacional do Estado de São Paulo para o período de 2007/2012. A área educacional no Estado é representada pelos gastos com a Secretaria de Educação; Universidades Estaduais, Centro Estadual de Educação Tecnológica "Paula Souza", além de Faculdades isoladas como a Faculdade de Marília, Faculdade de São José do Rio Preto e atividades educacionais que sejam desenvolvidas por outras instituições como a Fundação Casa. Para simplificarmos a 
apresentação identificamos apenas os gastos com a Secretaria de Educação, Universidades Estaduais e Centro Paula Souza.

O percentual aplicado durante todo o período foi de $30 \%$ com pequenas variações decimais. Entretanto, a participação de cada instituição nesse percentual apresenta algumas oscilações. Tais oscilações derivam do fato de que a vinculação das universidades esta ligada com a arrecadação de ICMS enquanto que a vinculação da Secretaria da Educação é definida pela arrecadação de total de impostos e transferências federais. Assim, dependendo do ritmo de crescimento da arrecadação do ICMS e dos outros impostos que compõe a base de arrecadação de impostos além das transferências federais, algumas oscilações ocorrem.

O fenômeno interessante do quadro esta relacionado com o crescimento do orçamento do Centro Tecnológico Paula Souza. Este Centro contempla tanto o ensino técnico de nível médio como o ensino superior de tecnologia através das Faculdades de Tecnologia. Dado que este tipo de ensino tem sido enfatizado pelos últimos Governos Estaduais, sua expansão é impressionante. Enquanto em 2007 o orçamento dessa instituição girava em torno de R $\$ 0,4$ bilhão em 2011 passava a representar R\$ 1,3 bilhão. Em termos percentuais em 2007 o orçamento da Paula Souza representava 2,4\% do orçamento total dos gastos com Educação e 2011 passaram a representar $4,8 \%$.

Desta maneira o desafio de financiamento das Universidades Estaduais apresenta algumas características bem identificadas. Em primeiro lugar existe uma determinação governamental para a expansão de vagas no ensino superior em decorrência do baixo grau de cobertura desse tipo de ensino na nossa população. Essa determinação traduz-se por pressões para a expansão de vagas no âmbito das três universidades estaduais e nas outras instituições de ensino superior publicas.

Por outro lado, a consolidação do FUNDEB ao elevar o percentual de aplicação de $15 \%$ para $20 \%$ aumenta a participação do ensino básico nos $30 \%$ constitucionais.

Adicionalmente, o significativo crescimento do Centro Paula Souza começará a exercer crescente pressão na vinculação constitucional. Em terceiro lugar a vinculação das Universidades Estaduais é mais frágil quando comparadas com a vinculação da Educação como um todo pois é estabelecida anualmente através da Lei de Diretrizes Orçamentárias. Em quarto lugar a vinculação é estabelecida em cima da arrecadação do ICMS e não do total de impostos e dependendo de como essa arrecadação evolui no conjunto dos impostos pode implicar em alterações na participação principalmente quando lembramos que a arrecadação de ICMS sempre representa o principal instrumento de guerra fiscal. 
Por ultimo, a medida que ocorra uma expansão do ensino superior, seja pela expansão das próprias universidades estaduais, seja pela expansão do Centro Paula Souza, ou outros mecanismos que possam ser idealizados, como por exemplo a proposta de criação da UNIVESP - Universidade Virtual do Estado de São Paulo, o resultado é que os 30\% que devem ser aplicados para o setor educacional podem ser insuficientes para contemplar todas essas pressões.

Esse conjunto de pressões estará mais ou menos forte dependendo da expansão da economia paulista que se traduza numa elevação dos recursos de tributos. Naturalmente, caso a economia paulista se expanda de maneira significativa de tal forma que o crescimento dos recursos provenientes desse crescimento permitam atender todas as pressões por expansão do ensino superior não haverá maiores problemas. Entretanto, caso as necessidades de crescimento do setor exijam um crescimento dos recursos numa proporção maior do que o proveniente do crescimento econômico, a situação de organização do orçamento do setor educacional ganha enorme complexidade. Neste caso, surgem duas alternativas: A pressão é acomodada através de uma expansão do percentual aplicado, o que significará uma maior disputa entre o setor educacional versus os demais setores, como por exemplo, saúde, transportes, segurança publica, etc.; ou alternativamente, haverá uma disputa interna no próprio setor educacional, entre o ensino básico e superior.

Outra dimensão do desafio do financiamento do Ensino Superior reside na questão de que a vinculação para as Universidades Estaduais Paulistas além de ser mais frágil do ponto de vista jurídico por ser definida na Lei de Diretrizes Orçamentárias, ela se apoia apenas da receita do ICMS.

O ICMS representa o principal imposto para a arrecadação dos Estados. Apesar dessa importância existe toda uma discussão sobre Reforma Tributária no Brasil que pode vir a alterar completamente a evolução da arrecadação desse imposto. Várias questões são debatidas, especialmente, a sobre a forma de incidência do ICMS. Atualmente o ICMS é arrecadado nos estados produtores das mercadorias (origem); entretanto, vários Estados defendem a alteração para que ele seja arrecadado no destino, transformando-se num imposto sobre consumo. Essa alteração prejudicará os principais Estados produtores, especialmente, o Estado de São Paulo. Provavelmente, caso alguma alteração, ocorra, ocorrerão compensações para o Estado na forma de transferências de recursos que não serão mais classificados como ICMS, e consequentemente, as Universidades Estaduais devem ficar atentas para toda a 
discussão de Reforma Tributária, pois pode alterar profundamente a base de seu financiamento.

Por outro lado, é fundamental que as próprias Universidades desenvolvam estratégias adequadas de elevar a oferta de seus serviços, especificamente, o ensino de graduação de maneira que preservando sua qualidade consiga identificarmos mecanismos que apresentem custos menores a fim de que esse crescimento seja maximizado.

\section{A AUTONOMIA UNIVERSITÁRIA E O FINANCIAMENTO DA UNIVERSIDADE DE SÃO PAULO}

Nesta seção, faremos alguns breves comentários a respeito dos impactos da autonomia universitária e da vinculação de recursos à arrecadação do ICMS para o desempenho do ensino e da pesquisa na Universidade de São Paulo.

Além da vinculação orçamentária, o Decreto da autonomia universitária, publicado em fevereiro de 1989, assegura às Universidades Estaduais Paulistas a autonomia didáticocientífica, administrativa, disciplinar, financeira e patrimonial. Dessa maneira, transfere-se às universidades a responsabilidade pela formulação e execução das políticas de pessoal, custeio e investimentos. ${ }^{\text {ii }}$ Essa maior independência, associada à clareza nas regras de financiamento e ao aumento da capacidade de planejamento no longo prazo, tiveram impactos amplamente positivos para o ensino e a pesquisa na USP. A Figura 2 abaixo mostra a evolução dos principais indicadores de desempenho da USP entre 1989 e $2011^{\text {iii }}$

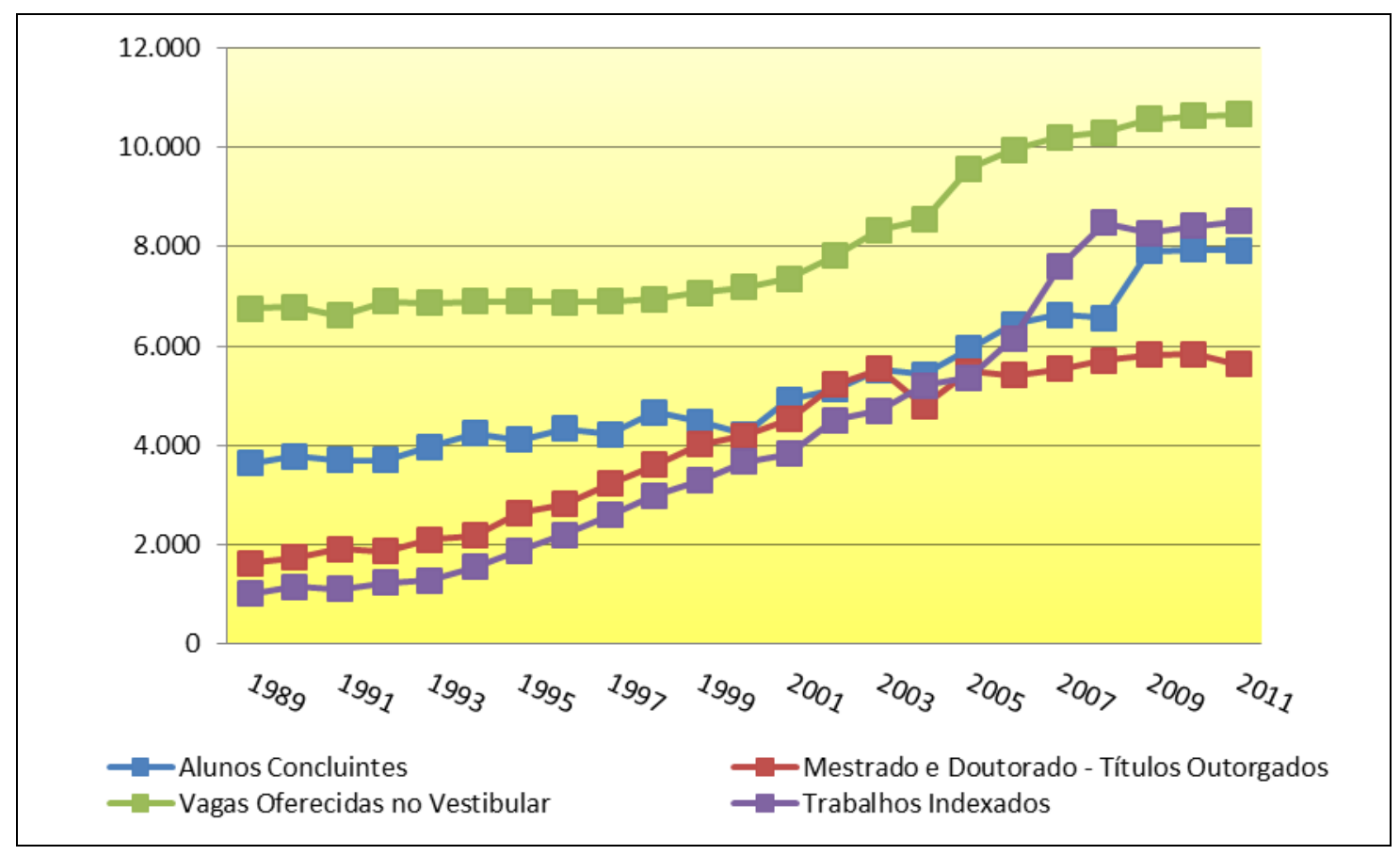

Figura 2 Evolução dos Principais Indicadores de Desempenho da USP após a Autonomia Universitária 
A partir da figura acima, nota-se um aumento significativo do número de vagas e de alunos concluintes nos cursos de graduação. Entre 1989 e 2011, o total de vagas oferecidas no vestibular da FUVEST aumentou cerca de 60\%, enquanto que o total de alunos concluintes teve um crescimento de $118 \%$. No que se refere à pós-graduação, o crescimento foi ainda mais expressivo com o número de títulos de mestrado e doutorado outorgados crescendo em torno de $245 \%$. Já com relação à produção acadêmica, o número de trabalhos indexados no Institute of Scientific Information (ISI) foi multiplicado por oito no mesmo período.

Nos últimos anos, com a melhora do desempenho da economia paulista, a vinculação de recursos à arrecadação do ICMS implicou num expressivo aumento nas liberações financeiras do Tesouro do Estado, cujo crescimento acumulado foi de 28,6\%, em termos reais, entre 2007 e 2011 (Figura 3).

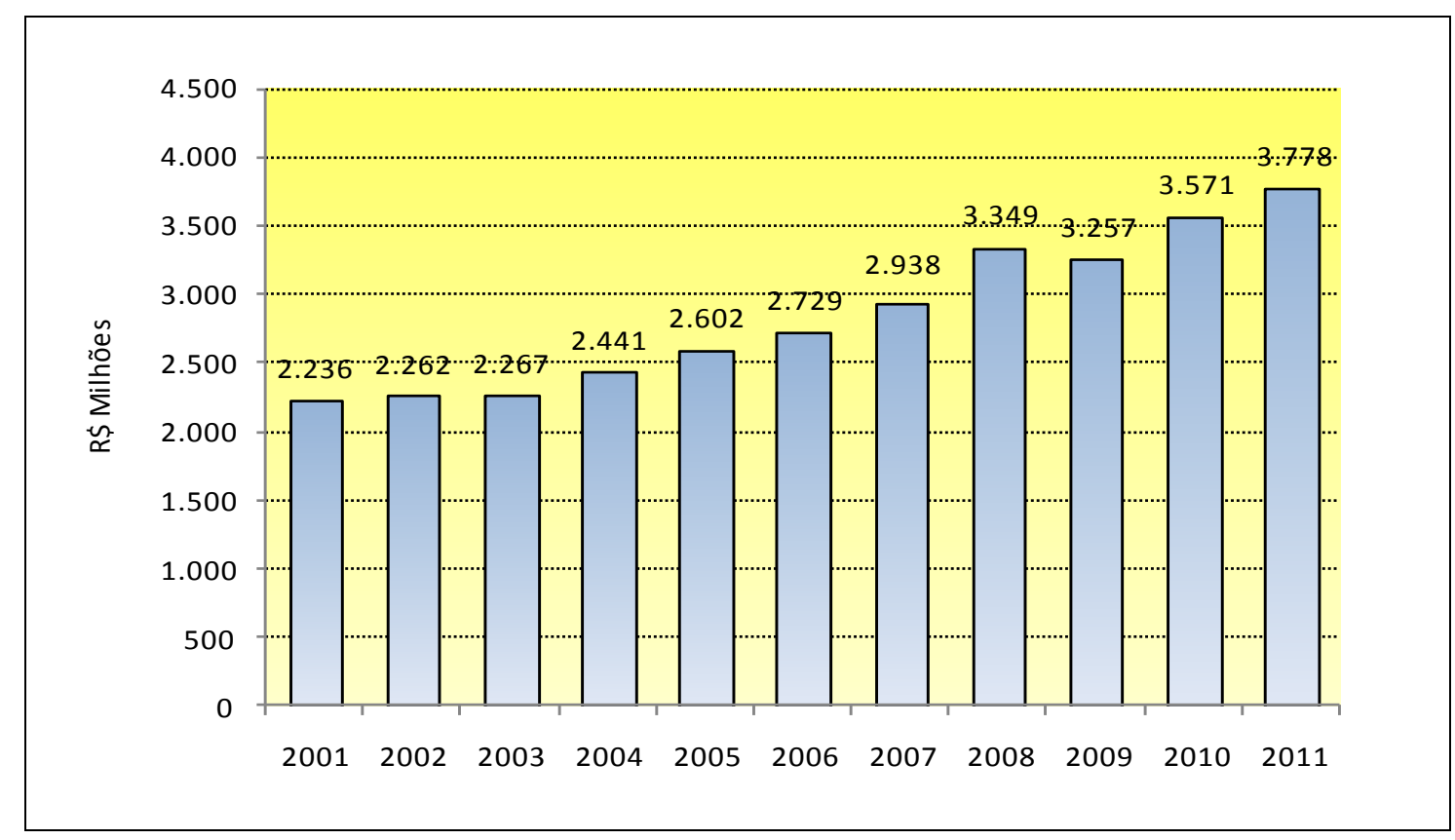

Figura 3 Valores Reais das Liberações Financeiras do Tesouro do Estado entre 2001-2011 (IPC/FIPE - Base 2011)

Esse crescimento do volume de recursos tem possibilitado à USP executar um amplo programa de recuperação e modernização de sua infraestrutura física, com a reforma e construção de novos prédios, aquisições de equipamentos, investimentos em novos laboratórios, etc. Além disso, tem sido possível também promover avanços na política de recursos humanos da Universidade, através da implantação e consolidação das novas carreiras dos servidores docentes e técnico-administrativos. Todos esses elementos são fundamentais para o estabelecimento de um programa de expansão de vagas sem o comprometimento da 
qualidade do ensino e da pesquisa, além de permitirem novos avanços da USP nos principais rankings internacionais.

\section{SUMÁRIO E CONCLUSÕES}

Como vimos o financiamento das instituições de ensino superior tem se alterado de maneira mais significa nos últimos anos. Atualmente, tais instituições contam com recursos extras aos orçamentos públicos identificados pelo pagamento de mensalidades dos alunos e venda de serviços para o setor produtivo privado. Entretanto, considerando de um lado o caráter fundamental do setor educacional para o desenvolvimento econômico bem como as externalidades positivas que ele apresenta, os recursos públicos são ainda responsáveis pela maior parcela do financiamento das instituições superiores.

Por outro lado, vimos que no Brasil, fruto da fragilidade financeira do setor público induziu o setor educacional a buscar proteger seu orçamento através das vinculações orçamentárias. No caso especifico das Universidades Estaduais Paulistas, desde o final da década de 80 estas contam com a vinculação do ICMS para a definição de seus orçamentos. Essa vinculação tem permitido que o orçamento dessas instituições tenha crescido de maneira significativa durante os últimos anos. Esse crescimento aliando-se com o excesso de demanda por serviços educacionais de nível superior tem exercido pressões para a expansão de vagas dessas instituições. Esse crescimento de vagas, fundamental para buscar reduzir esse excesso de demanda, aliado à criação do Fundef e posteriormente Fundeb tem pressionado o limite de $30 \%$ a ser aplicado no setor educacional. Esta pressão orçamentária interna no setor educacional pode representar desafios internos entre os setores de ensino básico e de ensino superior que serão agudizados caso a economia paulista reduza seu ritmo de crescimento. Caso nossa economia continue a se desenvolver de maneira razoável essas pressões podem ser administradas muito mais facilmente.

As Universidades Estaduais deverão estabelecer metas de crescimento especialmente das vagas de ensino de graduação e simultaneamente buscar alternativas de expansão dessas vagas que mantendo a qualidade possam encontrar formas menos onerosas.

\section{NOTAS}

i) Na realidade, o cálculo não é feito sobre o total da arrecadação do ICMS, pois subtrai-se o equivalente a $2,54 \%$ do total arrecadado desse tributo, fruto de uma outra lei que estabelece que as 
receitas provenientes do crescimento da alíquota de $17 \%$ para $18 \%$ deverão ser aplicadas em programas sociais, especialmente na área habitacional.

ii) Desde 1995, com base em decisão do CRUESP (Conselho de Reitores das Universidades Estaduais Paulistas), a Lei de Diretrizes Orçamentárias do Estado determina os seguintes percentuais de repasse para cada universidade: USP - 5,0295\%; UNESP - 2,3447\% e UNICAMP - 2,1958\%.

iii) Com algumas características próprias, esses ganhos também se verificaram na UNICAMP e na UNESP.

\section{BIBLIOGRAFIA}

BARR, N. Higher Education Funding. Oxford Review of Economic Policy, vol. 20, n.2, p.264283, mar. 2004.

JONGBLOE, B. Funding higher education: options, trade-offs and dilemmas. In: Fulbright Brainstorms 2004 - New Trends in Higher Education, Lisbon, Portugal. September 24-25, 2004.

JONGBLOED, B. Funding higher education: a view from Europe. Paper prepared for the seminar Funding Higher Education: A Comparative Overview, organised by the National Trade Confederation of Goods, Services and Tourism, CNC, Brasilia, out. 2008.

LEPORI, B., BENNINGHOFF, M., JONGBLOED, B., SALERNO, C. E STIG, S. Changing patterns of higher education funding: evidence from CHINC countries. Artigo elaborado para Changes in University Incomes: Their Impact on University-Based Research and Innovation (CHINC), nov.2005.

PEDROSA, R.H.L. Um Plano Diretor para o Ensino Superior Público do Estado de São Paulo. Revista Ensino Superior Unicamp, nov.2010. Disponível em: www.gr.unicamp.br/ceav/revistaensinosuperior/ed02_novembro2010.

SCHWARTZMAN, J. O Financiamento das Instituições de Ensino Superior no Brasil. Instituto de Estudos Avançados da Universidade de São Paulo, 2004. Disponível em: http://www.iea.usp.br/tematicas/educacao/superior/autonomiafinanciamento/schwartzmanfina nciamento.pdf. 